\title{
Non-linear ultrasonic defectoscopy of concrete structures for nuclear industry
}

\author{
Jaroslava Kot'átková ${ }^{1}$, Jan Patera ${ }^{2}$, Zbyněk Hlaváč ${ }^{3}$ \\ Research Centre Rez, Řež-Husinec, Czech Republic \\ E-mail: 'jaroslava.kotatkova@cvrez.cz (corresponding author)
}

\begin{abstract}
Concrete structures exposed to neutron radiation may exhibit cracking and deterioration, therefore it is needed to find appropriate non-destructive testing methods for assessing their structural integrity. Non-linear wave modulation spectroscopy (NWMS) was developed for non-destructive detection of cracks inside concrete. The goal of this paper is to compare the results of conventional non-destructive and destructive testing methods to the proposed non-linear NWMS method applied to ordinary concrete samples. The concrete damage by neutron radiation was simulated by thermal loading of the samples. Ultrasonic impulse method, resonance method, non-linear wave modulation method, compressive strength and flexural strength testing methods were applied.
\end{abstract}

Keywords: non-linear ultrasonic spectroscopy, concrete, neutron irradiation.

\section{Introduction}

Neutron irradiation of concrete causes damage in the microstructure of the material by the neutron interaction with the material itself and indirectly by the induced thermal heating, which is an issue in the case of biological shields used in nuclear industry (Field, Remec, \& Le Pape, 2015). Biological shielding concrete protects the area of reactor vessel and it is hardly accessible for conventional structural diagnostics, while any destructive tesing methods are out of consideration. Therefore, non-destructive testing plays vital role in the assesment of the material condition.

Non-linear spectroscopy is based on measuring the elastic-plastic response of the material whose plastic component is caused by microcracks. Part of this response may be caused by inhomogeneity of the material itself or the nonlinearity of the test system used, which is to be minimized in the measurement.

Nonlinear wave modulation spectroscopy (NWMS) rests on subsequent transmission of two signals. There are two different approaches of the signals inter-modulation, which can be used on concrete: a) mixing of low-frequency signal (c. 5-20 kHz) and a high-frequency one (c. 70-120 kHz) or mixing of two signals with similar frequencies.

The firstly emitted signal pulses change the width of a crack in dependence of the wave phase. During the compression wave phase the crack closes, meanwhile if the wave is in its tension phase the crack opens. Afterwards, the second signal is transmitted into the material, which is altered by the passage through the crack, more precisely its amplitude changes in dependence of the openness of the crack. If the crack is open at the time (as a result of its interaction with the first signal), the amplitude of the second signal decreases and in case of a closed crack, the amplitude increases. The recorded signal is then analysed using the Fast Fourier transform. For undamaged material there are only two input frequencies found in the obtained spectrum, which were altered only by linear wave dissipation and low atomic nonlinearities. The damage of the material will be demonstrated by the generation of side bands and higher harmonics. This procedure becomes an effective tool of non-destructive testing (Abeele, Desadeleer, De Schutter, \& Wevers, 2009; Wang, Lynch, \& Sohn, 2014).

This study compares the utility of nonlinear wave modulation spectroscopy with conventional non-destructive testing methods in relation to the results of destructive tests on conventinal concrete, which was subjected to heating in order to induce internal damage of the material.

\section{Materials and methods}

Materials

Four batches of ordinary concrete with w/c ratio 0.5 , silica sand and Portland cement CEM II 32.5 were subsequently mixed to manufacture four series of samples, which were intended to be used as a reference series, resp. series 
subjected to heating at temperatures $400{ }^{\circ} \mathrm{C}, 500{ }^{\circ} \mathrm{C}$ and $600{ }^{\circ} \mathrm{C}$. Six cylinders of diameter $100 \mathrm{~mm}$ and height 200 $\mathrm{mm}$, eight cubes of edge length $100 \mathrm{~mm}$ and nine prisms of dimensions $40 \times 40 \times 160 \mathrm{~mm}$ were prepared for each series. The samples were covered with plastic to avoid excess drying for two days, demoulded and then left on air to hydrate for 28 days.

\section{Methods}

After the 28-day period, all samples were weighed, measured for their dimensions and tested non-destructively. Afterwards, three series of samples were subjected to heating to $400{ }^{\circ} \mathrm{C}, 500{ }^{\circ} \mathrm{C}$ or $600{ }^{\circ} \mathrm{C}$, reference samples were kept at laboratory conditions at $24^{\circ} \mathrm{C}$. In the case of $400{ }^{\circ} \mathrm{C}$, the temperature was reached in 10 minutes. In both other cases, i.e. series subjected to heating $500{ }^{\circ} \mathrm{C}$ and $600{ }^{\circ} \mathrm{C}$, the maximum temperature was reached within 2 hours. The slower increment was chosen due to the crack, which occurred during heating of the series subjected to $400{ }^{\circ} \mathrm{C}$. The dwell time at the final temperature was two hours for all three cases, then the samples were left to naturally cool down. The procedure of dimensions and mass measuring and non-destructive testing was repeated again after the thermal treatment and also destructive tests were used.

Applied non-destructive methods were

- conventional ultrasonic impulse technique, following the Czech standards (ČSN 73 1371: Non-destructive testing of concrete - Method of ultrasonic pulse testing of concrete, 2012);

- resonance method (ČSN EN 73 1372: Non-destructive testing of concrete - Testing of concrete by resonance method on prisms, 2012);

- newly proposed ultrasonic method non-linear wave modulation spectroscopy (NWMS).

Destructive testing included

- determination of compressive strength on cubes, cylinders and prisms (ČSN EN 1015-11: Testing methods for mortar for masonry - Part 11: Determination of compressive and flexural strength of hardened mortars, 2000;

- ČSN EN 12390-3: Testing of hardened concrete - Part 3: Compressive strength, 2002);

-tensile strength on cubes (“ČSN 73 1318: Determination of tensile strength of concrete," 1986);

- flexural strength on prisms (ČSN EN 1015-11: Testing methods for mortar for masonry - Part 11: Determination of compressive and flexural strength of hardened mortars, 2000).

Non-linear parameter beta can be determined accodring to formula (1)

$$
\beta=\frac{A_{12}}{A_{1} \cdot A_{2}},
$$

here $\beta$ - non-linear parameter describing the degree of internal defects, e.g. microcracks $A_{12}, A_{1}$ and $A_{2}-$ amplitudes of peaks in frequency spectra $f_{12}, f_{1}$ and $f_{2}$, respectively.

Frequency of the side band (first intermodulation) is calculated as a sum of frequencies $f_{1}$ and $f_{2}$,

$$
f_{12}=f_{1}+f_{2} \text {. }
$$

In particular case, used for this paper, $f_{12}=f_{1}+f_{2}=153+180=333 \mathrm{kHz}$.

\section{Results}

Bulk density of all series of samples before any conditioning differed in the range of $3 \%$ which was within the range of standard deviation (Figure 3, blue line). The evaporation of free water and eventually the removal of bonded water caused the gradual decrease in bulk densities by up to $9 \%$ after the heating to $400{ }^{\circ} \mathrm{C}, 500{ }^{\circ} \mathrm{C}$ and $600{ }^{\circ} \mathrm{C}$ (Figure 3 , orange line). The removal of water and the physical and microstructural changes of concrete components due to heating, such as shrinkage of cement paste or volume expansion of siliceous aggregate caused cracking, being the most pronounced for samples heated to $600{ }^{\circ} \mathrm{C}$ (Figures 1 and 2). This was naturally manifested in the tensile splitting strength, flexural and compressive strength of samples.

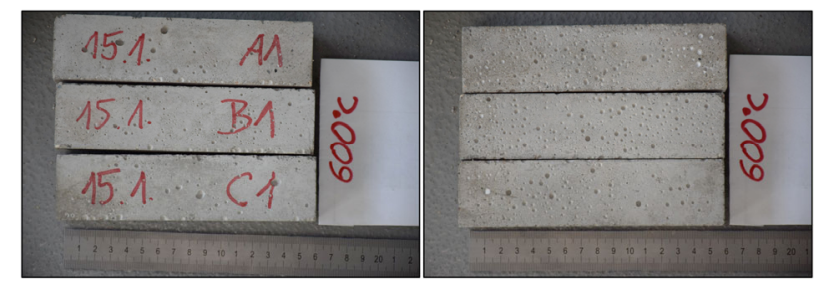

Figure 1. Photos of selected prism samples after heating to $600{ }^{\circ} \mathrm{C}$ (Samples are labelled with the date of preparation and casually selected marks composed by letters and numbers) 

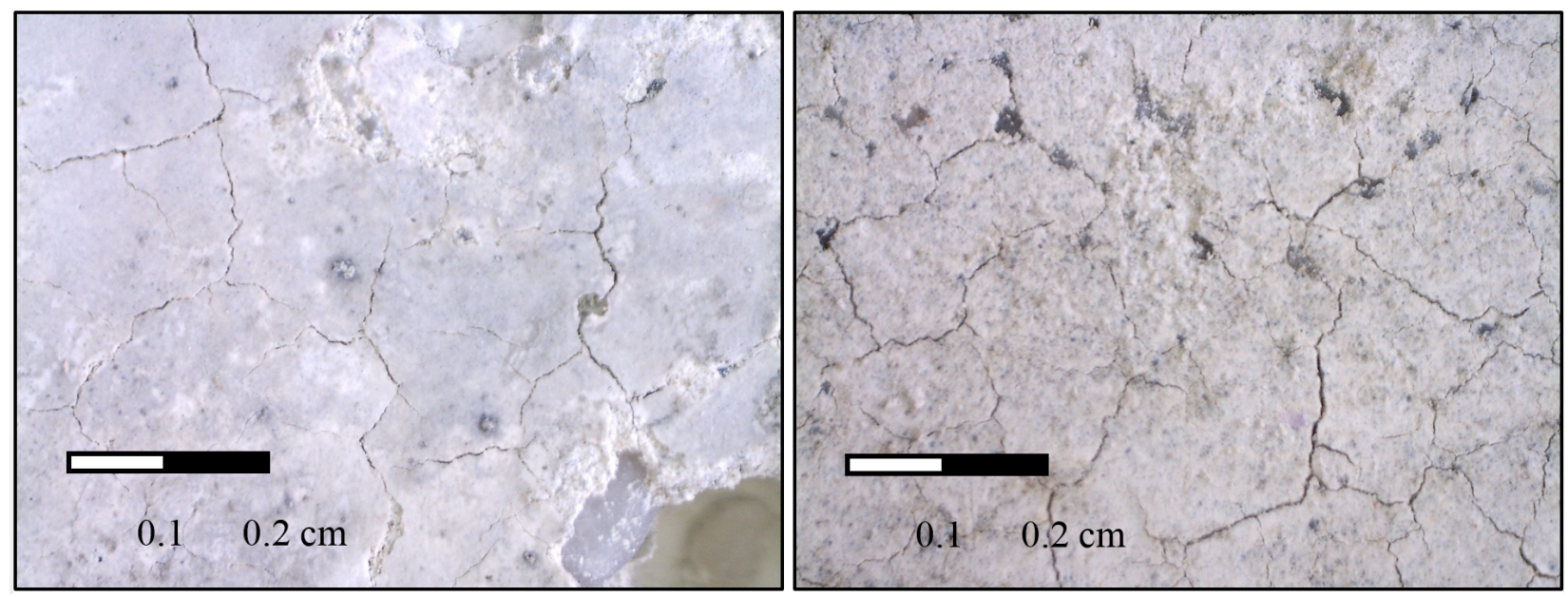

Figure 2. Detailed photos of A1 prism's surface from Figure 1 after heating to $600{ }^{\circ} \mathrm{C}$

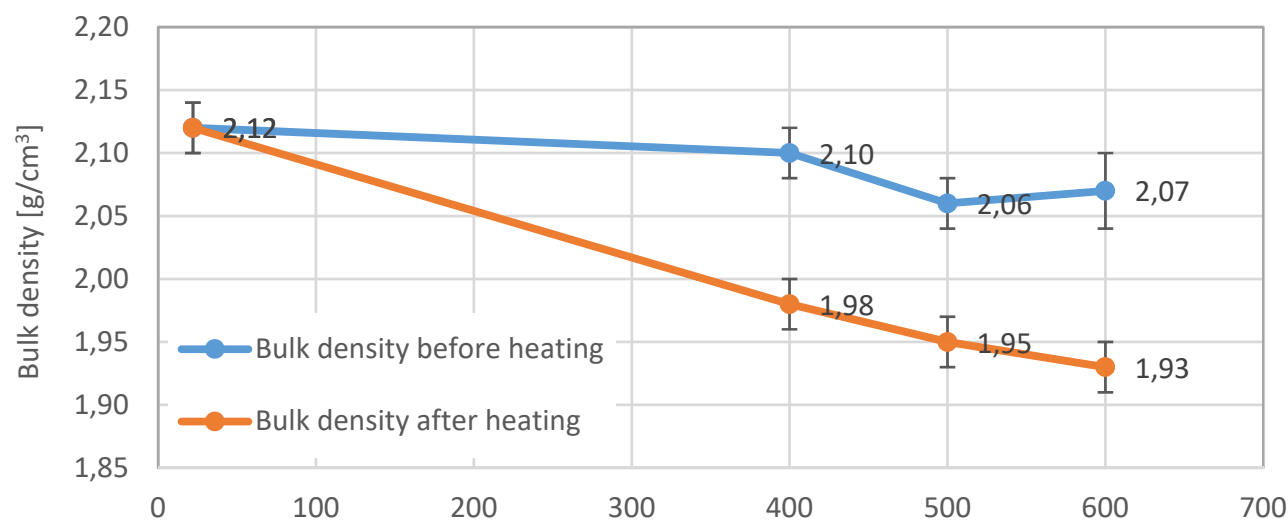

Figure 3. Bulk density of samples before and after heating

\section{Destructive testing}

Figure 4 presents the results of flexural and tensile splitting strength testing measured on prisms of dimensions $40 \times 40 \times 160 \mathrm{~mm}$ resp. on cubes $100 \times 100 \times 100 \mathrm{~mm}$. In case of flexural strength, there is a steep decrease in values, reaching only $10 \%$ of the initial value after heating to $600{ }^{\circ} \mathrm{C}$. Very similar trend was recorded for values of tensile splitting strength as the drop of values for samples heated to $600^{\circ} \mathrm{C}$ was by $89 \%$. Also hetaing to $400{ }^{\circ} \mathrm{C}$ resulted in creation of internal defects as the values of flexural and tensile strengh were about half the initial values.

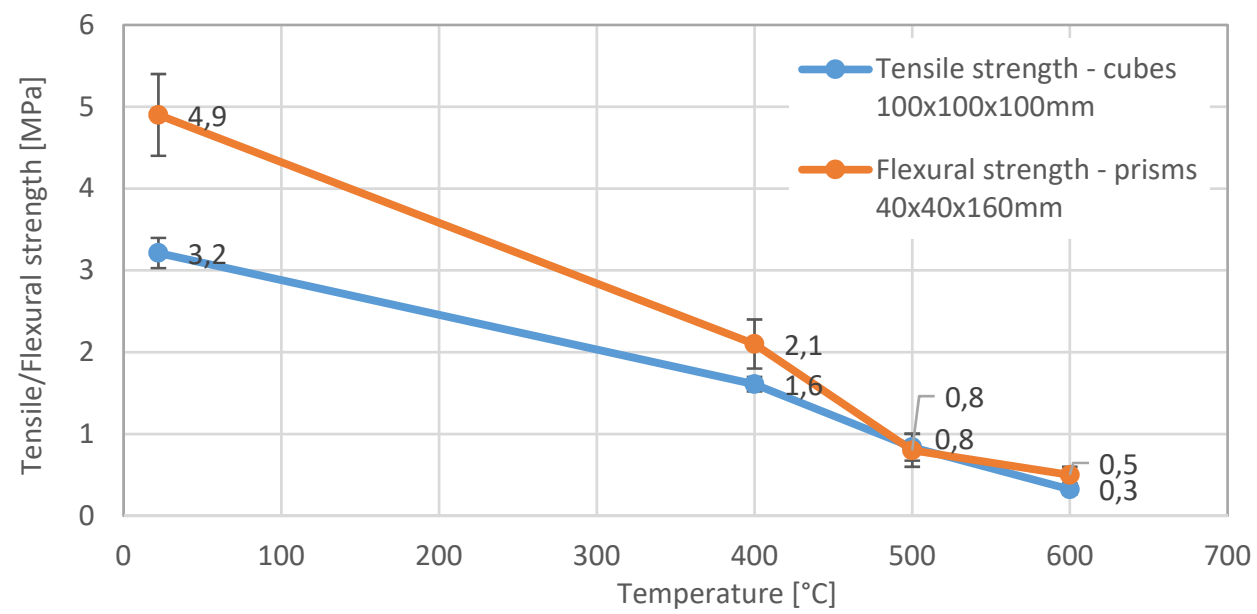

Figure 4. Tensile splitting and flexural strength of samples after heating, determined on cubes resp. prisms 


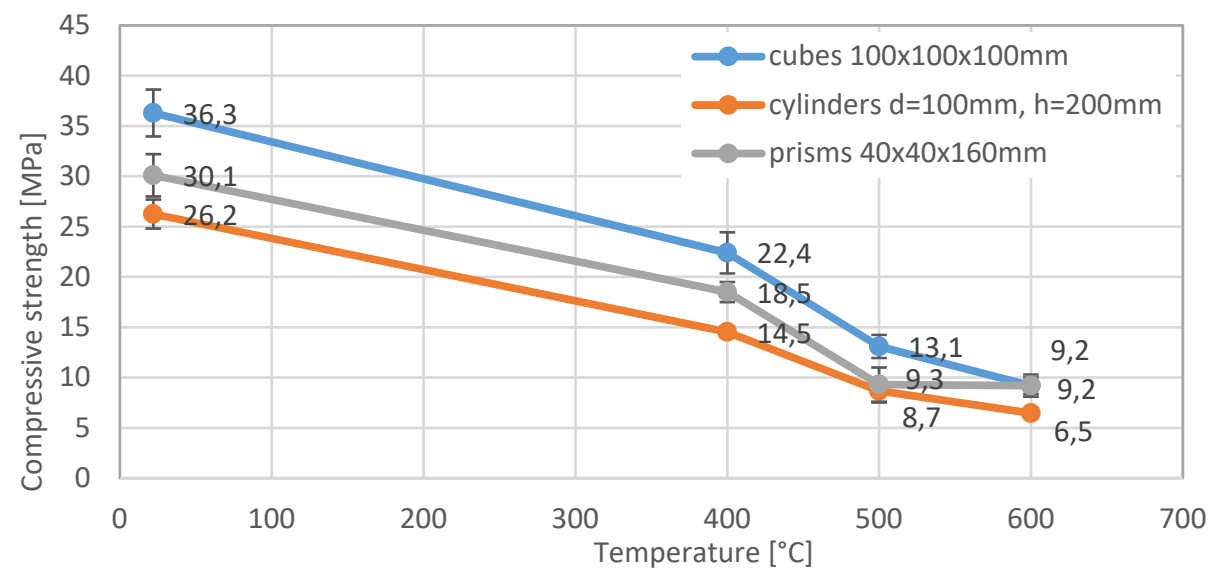

Figure 5. Compressive strength of samples after heating, determined on cubes, cylinders and prisms' fragments

Compressive strength was determined on cubes, cylinders and prisms, the values are given in Figure 5. Contrary to the results of tensile splitting and flexural strength, in this case the differences in values determined on samples of various shapes and dimensions were more or less similar. The strength determined on cylinders was always at about $30 \%$ lower than on cubes, while values on prisms were lower by $17 \%$ for reference state and $400{ }^{\circ} \mathrm{C}$, however for $500{ }^{\circ} \mathrm{C}$ the difference was $29 \%$ with almost the same value as in case of samples heated to $600{ }^{\circ} \mathrm{C}$, which on the other hand meant $0 \%$ difference when compared to values on cubes. Generally, when heated to $600{ }^{\circ} \mathrm{C}$ there was a drop in values in the range of $70-75 \%$ for all samples when compared to the reference samples.

\section{Non-destructive testing}

Figure 6 presents the results of conventional non-destructive testing methods - ultrasonic impulse technique, which gives the modulus of elasticity $\left(E_{\mathrm{bu}}\right)$ and impact-echo giving modulus of elasticity in longitudinal direction $\left(E_{\mathrm{brL}}\right)$ and transversal direction $\left(E_{\mathrm{brf}}\right)$. All values were determined on both prisms $40 \times 40 \times 160 \mathrm{~mm}$ and cylinders $d=100 \mathrm{~mm}$, $h=200 \mathrm{~mm}$, given values are average values with standard deviations. There are insignificant differences in values of modulus of elasticity determined by the different methods. Moreover, the decrease in values more or less relates to a linear dependence in all cases. Also, the decrease in values is profound and so easily detectable, as the drop in values between reference samples and samples heated to $600^{\circ} \mathrm{C}$ is by $97 \%$.

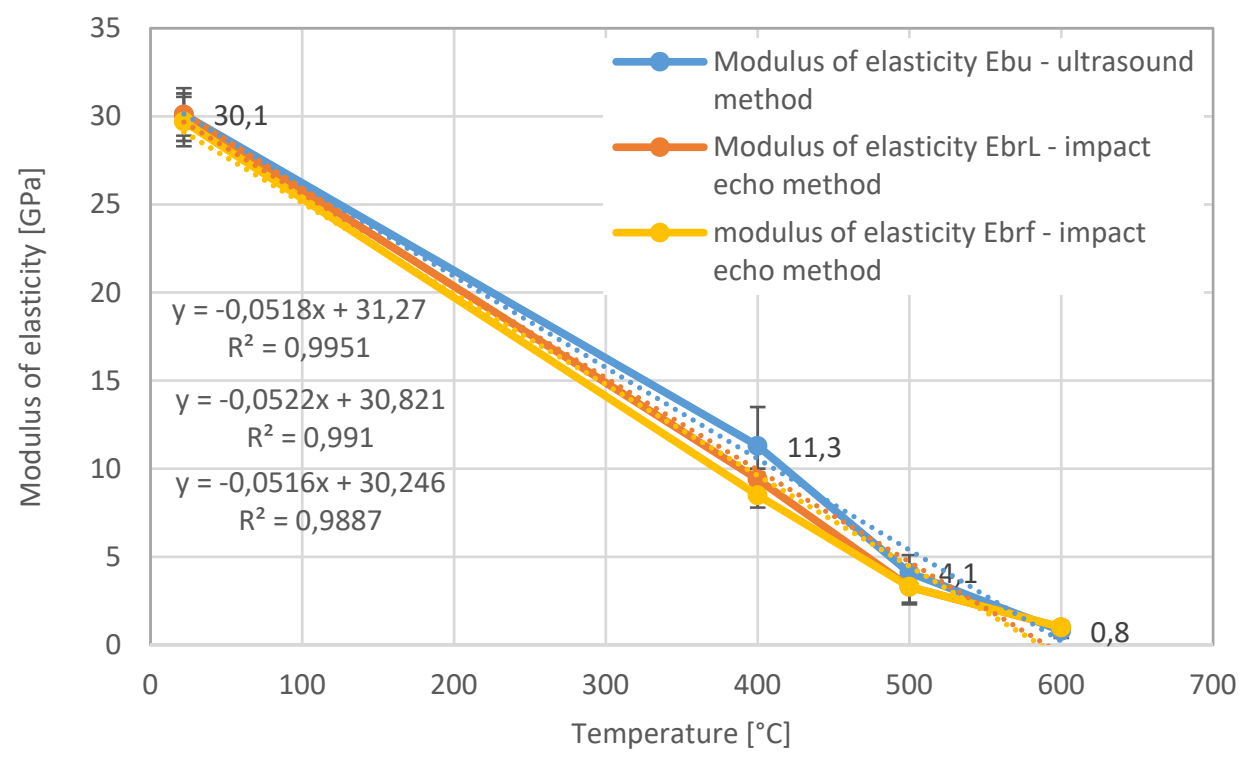

Figure 6. Modulus of elasticity measured non-destructively by conventional ultrasound method $\left(E_{\mathrm{bu}}\right)$ and resonance method in longitudinal direction $\left(E_{\mathrm{brL}}\right)$ and transversal direction $\left(E_{\mathrm{brr}}\right)$ 


\section{Non-linear non-destructive testing}

Results obtained by the newly developed method NWMS are presented in Figure 7 in logarithmic scale, again measured on all samples differing in shape and dimensions, i.e. on cubes, prisms and cylinders. Six values were determined for each sample in each group of samples. Average values together with standard deviations were calculated. There is a rise of the parameter beta, which represents non-linearity caused by internal defects, with rising conditioning temperature. The differences in results obtained on different samples' shape and dimensions samples considering the error bars are manifested only in case of reference.

Table 1. Evaluation of non-linear parameter beta for 4 selected prisms

\begin{tabular}{|c|c|c|c|c|}
\hline Conditions & Reference & $400{ }^{\circ} \mathrm{C}$ & $500{ }^{\circ} \mathrm{C}$ & $600{ }^{\circ} \mathrm{C}$ \\
\hline Amplitude $A_{12}[\mathrm{~V}]$ & 0.0000187 & 0.00004829 & 0.0000128 & 0.000001024 \\
\hline Amplitude $A_{1}[\mathrm{~V}]$ & 0.0342 & 0.0301 & 0.0126 & 0.000812 \\
\hline Amplitude $A_{2}[\mathrm{~V}]$ & 0.0712 & 0.0214 & 0.0058 & 0.00033 \\
\hline Parameter beta $\left[\mathrm{V}^{-1}\right.$ ] according to (1) & 0.0076 & 0.0750 & 0.1752 & 3.8215 \\
\hline
\end{tabular}

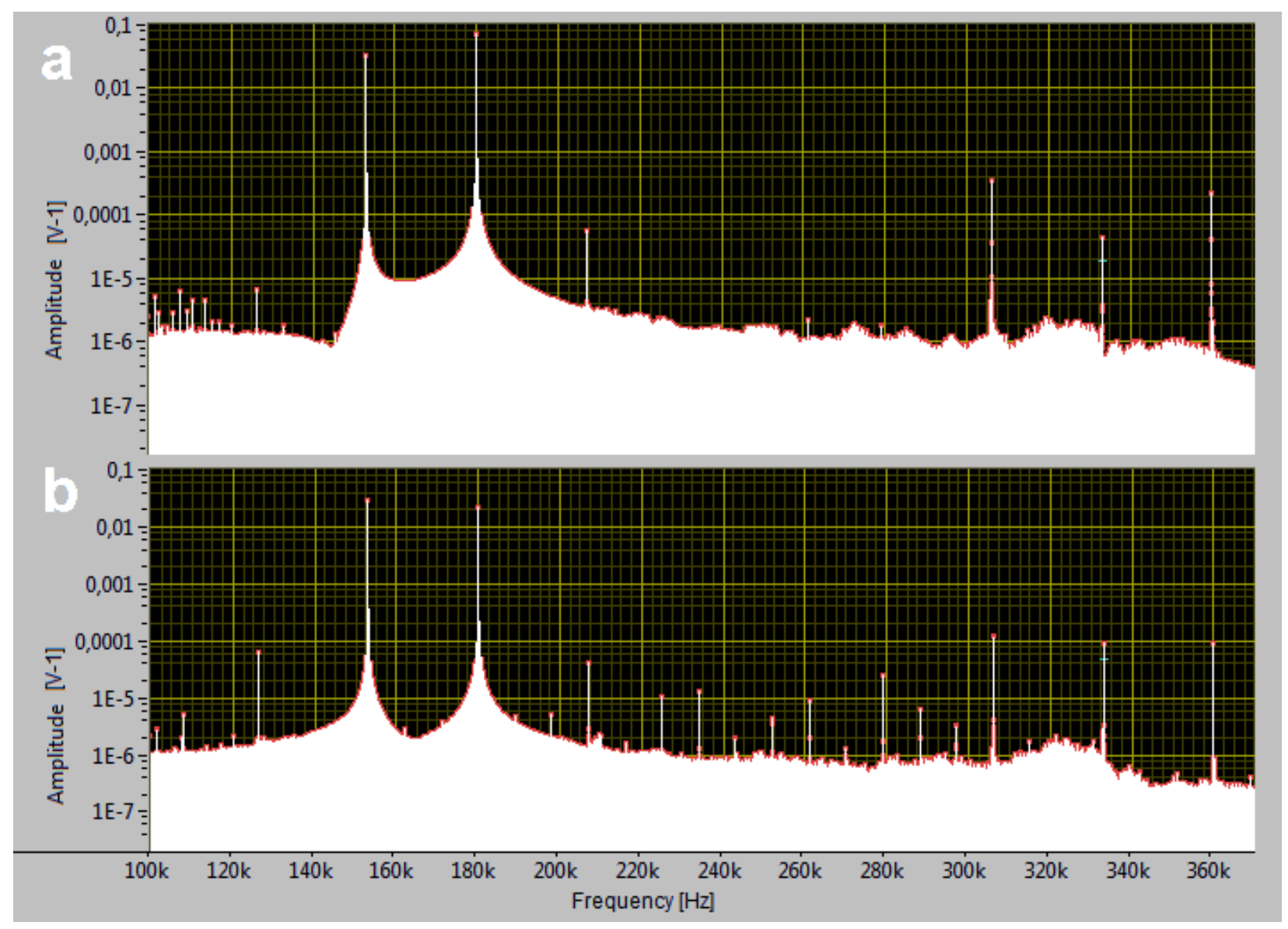

Figure 7. Frequency spectra of prism A1 before a) and after $400{ }^{\circ} \mathrm{C}$ heating b)

In Table 1, there are amplitudes $A_{12}, A_{1}$ and $A_{2}$, measured in selected prisms - reference, after $400{ }^{\circ} \mathrm{C}, 500{ }^{\circ} \mathrm{C}$ and $600{ }^{\circ} \mathrm{C}$. There are visible differences among the amplitudes which belong to frequency peaks $333 \mathrm{kHz}=f_{12}$, $153 \mathrm{kHz}=f_{1}$ and $180 \mathrm{kHz}=f_{2}$, see Figure 8. Finally, non-linear parameter beta and its calculation is provided in Table 1 according to formula (1).

Values in the Figure 8 belong to all the tested series in average. The ratio to the reference series is 14.4 for $400{ }^{\circ} \mathrm{C}$, 16.8 for $500{ }^{\circ} \mathrm{C}$ and 31.0 for $600^{\circ} \mathrm{C}$. This gives a clear picture about the relationship between the damage and the presence of the microcracking, i.e. in case of the first occurence of microcracks non-linear parameter beta rises rapidly, approximately ten times, after the cracks development and widening there is not so significant increment of beta, which rises "only" by several tens of percents afterwards. 


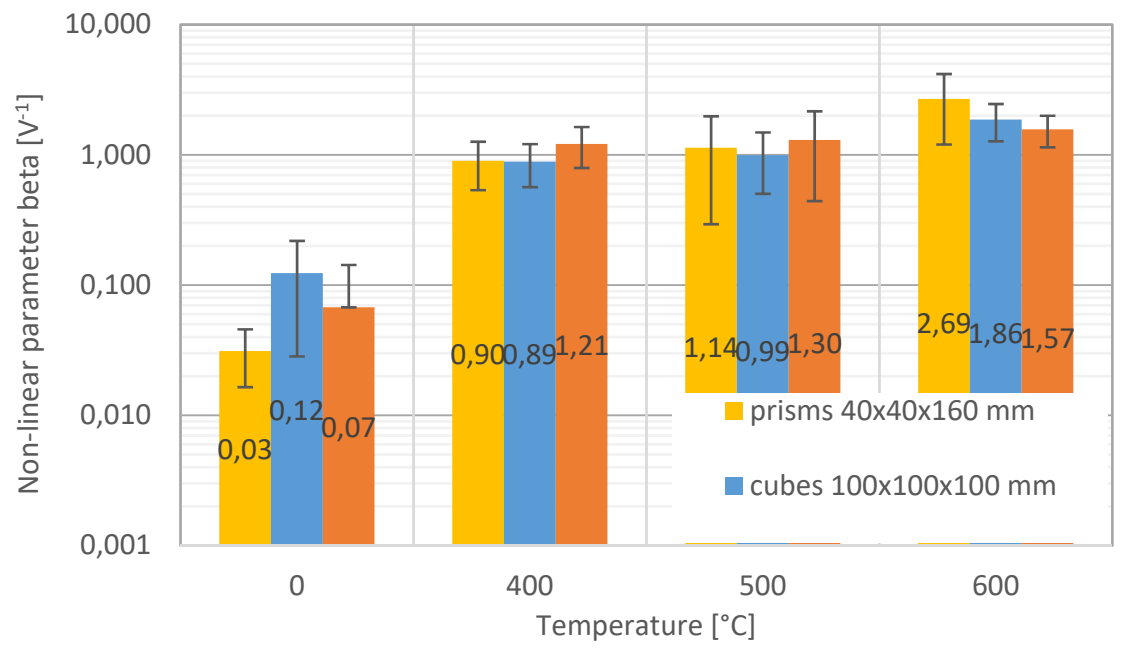

Figure 8. Parameter beta $\left[\mathrm{V}^{-1}\right]$ as an indicator of non-linearity measured by NWMS displayed in logarithmic scale

\section{Conclusions}

The paper aims to present a newly developed non-linear method for non-destructive testing of concrete NWMS and compare its utilization with conventional non-destructive methods used in civil engineering. The methods were applied on ordinary concrete samples of different shapes and dimensions (cubes, cylinders and prisms) subjected to thermal loading at temperatures $400{ }^{\circ} \mathrm{C}, 500{ }^{\circ} \mathrm{C}$ and $600{ }^{\circ} \mathrm{C}$ to initiate the uprise of defects inside concrete structure, in comparison to reference samples (without heating). Destructive test were performed to complement the database.

- Flexural and tensile strength decreased by $90 \%$ when heated to $600{ }^{\circ} \mathrm{C}$, the shape and dimensions of samples influenced the values for reference samples and samples subjected to $600{ }^{\circ} \mathrm{C}$, while samples heated to $400{ }^{\circ} \mathrm{C}$ and $500{ }^{\circ} \mathrm{C}$ did not present such high differences in values;

- The drop in compressive strength when heated to $600{ }^{\circ} \mathrm{C}$ was by $70-75 \%$, while the difference between values determined on different groups of samples were approximately the same for all heating states;

- Values of modulus of elasticity obtained by conventional ultrasound and resonance methods decreased by $97 \%$ when heated to $600{ }^{\circ} \mathrm{C}$ and showed a linear dependence of its values on the conditioning temperature;

- Non-linear parameter beta obtained by NWMS did not show any clear dependence on temperature as the rest of the methods, but proved itself to be very sensitive to the presence of any defects in the internal structure of concrete, as the rise of values for samples heated to $400{ }^{\circ} \mathrm{C}$ when compared to reference samples was by one order of magnitude.

\section{Acknowledgements}

This work has been supported by the Ministry of Education. Youth and Sport in the Czech Republic - LQ1603 Research for SUSEN and internal project: Monitoring of concrete cracks via neutron noise analysis.

\section{References}

Abeele, K. Van Den, Desadeleer, W., De Schutter, G., \& Wevers, M. (2009). Active and passive monitoring of the early hydration process in concrete using linear and nonlinear acoustics. Cement and Concrete Research, 39(5), 426-432. https://doi.org/10.1016/j.cemconres.2009.01.016

Czech technical standard. (1986). Determination of tensile strength of concrete (ČSN 73 1318).

Czech technical standard. (2000). Testing methods for mortar for masonry - Part 11: Determination of compressive and flexural strength of hardened mortars (ČSN EN 1015-11).

Czech technical standard. (2002). Testing of hardened concrete - Part 3: Compressive strength (ČSN EN 12390-3).

Czech technical standard. (2012). Non-destructive testing of concrete - Method of ultrasonic pulse testing of concrete (ČSN 73 1371).

Czech technical standard. (2012). Non-destructive testing of concrete - Testing of concrete by resonance method on prisms (ČSN EN 73 1372).

Field, K. G., Remec, I., \& Le Pape, Y. (2015). Radiation effects in concrete for nuclear power plants - Part I: Quantification of radiation exposure and radiation effects. Nuclear Engineering and Design, 282, 126-143. https://doi.org/10.1016/j.nucengdes.2014.10.003

Wang, M. L., Lynch, J. P., \& Sohn, H. (Eds.) (2014). Sensor technologies for civil infrastructures (1 ${ }^{\text {st }}$ ed., vol. 2). Burlington. https://doi.org/10.1533/9780857099136.1 